\title{
Omissions as Possibilities ${ }^{1}$ \\ Sara Bernstein
}

(Penultimate version; final version forthcoming in Philosophical Studies)

\section{Introduction}

Last week I watered my plant, causing it to look green and healthy. But this week I failed to water it, causing it to look brown and wilted. My watering the plant was a "positive" event, but what, exactly, was my omission to water it?

Causal claims involving omissions - roughly, events that fail to occur-- are commonplace, but they are metaphysically puzzling along several dimensions. There is a basic metaphysical question: what are omissions? There is a semantic question: what do omissive causal claims denote? There is a causal question: do omissions participate in causal relations? And there is a selectivity question: if omissions do participate in causal relations, exactly which ones do? A well-developed metaphysics of omissions will have something to say about each of these questions. Additionally, an ambitious metaphysics of omissions will provide a foundation that reflects commonsense moral data about omissions, including moral differences between omissions, and the particular omissions for which an agent is morally responsible.

Broadly speaking, there are three options in the logical space of views of what omissions are: (i) omissions are actual things, (ii) omissions aren't anything at all, and (iii) omissions are possible things. This paper defends option (iii). I present and develop an analysis of omissions as de re possibilities of actual events. My goal will be to show that taking omissions to be possibilities satisfies most explanatory and metaphysical desiderata for a theory of omissions. I will not attempt to answer all of the above questions; nor will I attempt to give an account of causation by omission per se. Rather,

\footnotetext{
1 This paper has benefitted enormously from comments by Mark Heller, Carolina Sartorio, Xiaofei Liu, Rachael Briggs, and Stephen Kearns. I also thank Mark Balaguer, Randy Clarke, Owen Flanagan, Daniel Nolan, Alex Rosenberg, and Walter Sinnott-Armstrong for extensive conversation and feedback, and audiences at the Bellingham Summer Philosophy Conference, Australian National University, Melbourne University, 2012 Pacific APA, Rocky Mountain Ethics Congress, Triangle Area Philosophy Symposium, Arizona State University, Boise State University, and Cal State-Los Angeles.
} 
my goal is to show why the framework of unactualized possibility is the best metaphysical model for the hidden structure of our omissive causal claims.

Roadmap: in §1, I separate and refine several puzzles concerning omissions. In $\S 2$, I argue against two existing views on the metaphysics of omissions. In $\S 3$, I present and develop a positive view about what omissions are. In $\S 4$, I show how taking omissions to be unactualized possibilities accounts for two pieces of commonsense moral data: moral differences between omissions, and special cases I call norm selected pairs. I diagnose Peter Singer's argument for giving to charity as a norm selected pair, and I discuss the consequences of this result. I also address some limitations of the framework.

\section{Puzzles about Omissions}

First puzzle: how can something that doesn't occur cause something else to happen? For example, how can a failure to water the plant cause the plant to become brown and wilted? Theories of causation according to which the causal relation involves some sort of "oomph" or transfer of conserved quantity from one thing to another ${ }^{2}$ do not accommodate omissions as causal relata. There is no thing or event from which oomph can be transferred, so either omissions are not causes (and our causal talk about them fails to capture something metaphysically meaningful), or oomph-y theories of causation are false.

This puzzle is a symptom of a deeper metaphysical conflict between two mutually inconsistent commitments about being and causation. About being, it is natural to be drawn to the view that only items in "positive" being - tables, meetings, actual goingson - exist or occur. But it is also natural to be drawn to the view that omissions- -things that don't occur-are causes. Call this puzzle CONFLICT.

Second puzzle: the counterfactual account of causation, upon which $c$ is a cause of $e$ if $e$ counterfactually depends on $c$, admits far more omissions as causes than are intuitively so. Unlike oomph-y theories of causation, omissions easily fit into counterfactuals of the form

\footnotetext{
${ }^{2}$ For example, that of Dowe (2000).
} 
$\sim \mathrm{A}->\sim \mathrm{C}$

such as

If the technician hadn't failed to perform the safety check, the plane wouldn't have crashed.

But other omissions, such as

If Barack Obama hadn't failed to perform the safety check, the plane wouldn't have crashed.

also generate counterfactual dependence between putatively irrelevant omissions (such as Barack Obama's failing to perform the safety check) and the effect. Such omissions come out as causes on the counterfactual view, even when they are not, intuitively, causes. This is known more broadly as the "problem of profligate omissions." Admitting any omissions as causes seems to admit all omissions - even the nonsalient ones - as causes.

One might be tempted to say that even if both omissions (the technician's failing to perform the safety check, and Barack Obama's failing to perform the safety check) are causal, the technician's omission is the more salient one. Let's call this intuition SALIENCE. The problem is that SALIENCE isn't grounded causally: since both omissions generate counterfactual dependence, both come out as causes simpliciter.

A slightly different way of framing the problem is the following. It seems like the omission "belongs," in some sense, to the airline technician but not to Barack Obama. Intuitively, when we ask what should have happened rather than, say, the technician snacking during his work shift, the natural answer is that he should have performed the safety check. The unlikely answer is that Barack Obama should have performed the safety check. Metaphorically, we can see this problem as one of attachment: how does the omitted event (the safety check) "attach" to the technician and not to Barack Obama? Call this problem ATTACHMENT.

Final puzzle: omissions appear to be metaphysically privileged absent things, not

\footnotetext{
${ }^{3}$ For further discussion of this problem, see Thomson (2003), McGrath (2005) and Sartorio (2005), (2009).
} 
any old absent things. ${ }^{4}$ Random absent things include a floating City of St. Louis above Paris, a golden mountain, and the 2006 Great War of Nebraska. The omissions that we select in causal contexts seem different from any old non-occurrence. But in virtue of what are they different? The conceptual difference is between something that was "close" to occurring (in some contextually specified sense of "close") such as the technician's safety check, and something that didn't occur at all and wasn't ever close to occurring, such as a goblin war. Metaphysically, what marks off the difference between random non-beings and events that were close to coming into being (or "supposed" to occur)? Call this puzzle PRIVILEGED ABSENCES, due to the idea that omissions are a metaphysically privileged sort of non-occurrence.

2. The Metaphysics of Omissions: Lay of the Land

The first puzzle involves a conflict between two commonsense beliefs. The latter three puzzles call into question why one omission is the causally relevant non-happening out of an abundance of them; they are "selection puzzles" about narrowing the pool of metaphysically salient objects. While it seems implausible that metaphysics apart from context will entirely explain these puzzles, a well-developed metaphysics of omissions should have something to say about most of them. But current views don't fare well in this regard.

In attempting to resolve CONFLICT and ATTACHMENT, the initial temptation is to identify omissions with positive being. For example, one might hold that the omission of the safety check just is the technician's coffee-drinking or whatever he was doing in place of the safety check. Many omissions have something going on "in the place" of the event that does not occur. Should an omission be identified with the event that happens in its place?

No. First reason: an omission is multiply realizable with respect to activity, time, and spatial location, which means that it cannot be reduced to a single event that occurred "in its place." We cannot look to the activity that the technician was doing in place of the

\footnotetext{
${ }^{4}$ Terminological note: here I use "absence" to mean anything that doesn't occur, and "omission" to mean a causally salient event. In this usage, omissions are a privileged subclass of absences distinguished by causal salience. I discuss this distinction at length further below.
} 
safety check, and call that the omission, for any number of events could have been the omission. Joe could have been doing a jig or reading a book, and yet the safety check still would not have occurred.

We cannot look to the time when the safety check was to occur and call whatever fills that period the omission, for there are many periods of time in which the failed event could have occurred. Suppose that the safety check takes a half hour, and the time in which the technician could have performed it was between $1 \mathrm{pm}$ and $3 \mathrm{pm}$. To which half hour period does the omission reduce? 1-1:30pm? 1:47-2:17pm? Each half-hour period between $1 \mathrm{pm}$ and $3 \mathrm{pm}$ was a time at which the safety check could have occurred.

We cannot look to the place where the safety check was to occur and call that the omission, for there are many places on the tarmac that the safety check could have occurred. (We can even imagine an exotic scenario in which the technician performs the safety check from far away using a distance-controlled robot.)

"Negative" events are more flexibly realized than positive events. Fixing the landing gear can only be realized by someone or something fixing the landing gear, whereas the failure to perform the safety check can be realized by any event that is not a safety check but is compatible with a safety check occurring-countless events happening in the world between 1 and $3 \mathrm{pm}$.

The strategy of reducing omissions to positive events is ineffective due to the abundance of candidates for the reduction base, and no principled reason for choosing one positive event over another. In response, one might try to modify the positive reduction strategy in one of two ways. First, one might say that every actual event where and when the omitted event doesn't occur is part of the omission. On this view, the conjunction of every event that isn't the omitted event (say, every event that isn't the safety check) is the omission. Call this The Conjunctive Event Strategy.

The Conjunctive Event Strategy fails to solve any of the selection puzzles, since it doesn't select any particular event at all. For any omitted event (such as the failure to perform the safety check), a large portion of the world is the omission, since almost every event will have the property not being the safety check. And all of these omissions are 
roughly metaphysically the same. There's no accounting for PRIVILEGED ABSENCES, since no single absence is privileged out of the conjunction. There's no explanation of SALIENCE, since every part of the conjunction of events is part of the omission. And there's no account of ATTACHMENT, since the omission would attach to many indiscriminate actual events.

One might also hold that the omission is a disjunction of the events that aren't the omitted event. For example, the failure to perform the safety check is either the technician's snacking OR the technician's dancing OR the technician's eating lunch. Call this the Disjunctive Event Strategy. This modification is more promising, since multiple events, but not an abundance of them, are eligible to count as the cause.

But there is an intuitive presumption against disjunctive causes: it seems strange to say that a plant-watering or a gunshot caused the plant's survival, just as it seems strange to say that the technician's snacking or the President's eating lunch caused the plant to die. ${ }^{5}$ And every positive event will be part of a potentially infinite disjunction of causes, creating a new and different problem of profligate omissions, thus counterbalancing the theoretical payoff of such a view with an equally costly metaphysics. Neither variation on the positive event reduction strategy is satisfying.

Another reason we cannot identify omissions with positive events is that the relevant counterfactual dependency holds between the failing to perform the safety check and the crashing, not necessarily between the coffee drinking and the crashing. No single "positive" event (the dancing or the driving or the cooking) generates an antecedent that makes the counterfactual intuitively true. For it is not necessarily true that if the technician had not snacked, the plane would not have crashed. It is not the case that the snacking causes the plane crash. It is the omission, rather than the positive event, which correctly figures into the causal claim. Identifying omissions with positive being doesn't actually solve CONFLICT, since the items in positive being to which the omissions reduce aren't necessarily the causes of the relevant effects.

Rather than reduce omissions to particular bits of "positive" being, one might

\footnotetext{
${ }^{5}$ For a view that argues in favor of disjunctive causes, see Sartorio (2006).
} 
instead think that omissions are non-beings. Proponents of the non-being view ${ }^{6}$ hold that when someone omits to act, there's nothing in the world that is the omission. For example, when I fail to water a plant, there is nothing in the world - an event in its place, a fact, a negative state of affairs, a spacetime region - that is the omission.

But the non-being view doesn't resolve any of the four puzzles. CONFLICT is unresolved by the non-being view, since non-beings cannot be causes. ATTACHMENT is not accounted for, since there are no omissions to attach to positive being. Nor is PRIVILEGED ABSENCES resolved, for the following reason: it is plausible to assume that there is only one way not to exist. Even if we make sense of the idea that there are multiple ways of being, presumably there are not multiple ways of non-being. All nonbeings have the same ontological status. Unicorns do not exist in just the same way that the safety check does not exist. If omissions are absences of being, then they are all precisely the same kind of non-being. And so we cannot account for the idea that some omissions are "closer" to being than others. SALIENCE is also unresolved: if all omissions do not exist in precisely the same way, then there is nothing in virtue of which some omissions are more causally salient than others.

I conclude that the two common standing views on omissions - that omissions are actual beings and that omissions are absences of being - do not meet the explanatory desiderata for a metaphysics of omissions. I turn now to a positive proposal.

\section{The Proposal}

\subsection{Omissions as Three-Part Entities}

Our natural concept of an omission in a causal context is already counterfactual: an omission is an event such that had it occurred, it would have caused another event to occur. For example, in determining the causal structure of the plane-crash case, we look to a possible world where the omitted event (the safety check) does occur, and figure out what happens in that world as a result (the plane landing safely.)

Let's take that modal intuition a step further. Reject the idea that omissions

\footnotetext{
${ }^{6}$ Such as Clarke (2010) and (2012).
} 
identify actual events or don't identify anything at all. Instead, consider the idea that omissions partially pick out possible events. Specifically, identifying the omission of an event $e$ at the actual world identifies $e^{*}$ 's occurrence at a possible world, where $e^{*}$ is the event that does not occur at the actual world. Context identifies $e^{*}$ as a counterpart of $e$, an event in the actual world. The idea is that an omissive causal claim in part identifies the unactualized possibility of the omitted event's occurrence. For example, "The technician failed to perform the safety check" partially identifies the technician performing the safety check at a possible world. And "I failed to water the plant" partially identifies my watering the plant at a possible world.

I'll now refine and clarify. First, a bald statement of the view: an omission is a tripartite metaphysical entity comprised of an event at a possible world, ${ }^{7}$ an event at the actual world, and a counterpart relation between them. ${ }^{8}$ Actual events have omitted events as de re possibilities. An omissive claim contextually identifies a counterpart relation between an actual event and a possible one. For example, every actual half-hour period in which the technician could have performed the safety check in the actual world has, as a counterpart, a safety check in a possible world. The omissive causal claim identifies the relationship between what the technician was doing in every half hour period when he could been performing the safety check, and what he could have been doing during those periods.

This analysis of omissions makes use of two major modal notions: counterpart theory, and closeness of worlds. I'll discuss each in turn.

I am applying a counterpart-theoretic treatment to events. ${ }^{9}$ Such a treatment includes several commitments. Primarily, it implies that events have de re modal

\footnotetext{
${ }^{7}$ For simplicity, I am assuming that events are the causal relata.

${ }^{8}$ A natural question arises: why not just use possible worlds without counterpart theory? Several reasons, in my view: first, counterpart theory provides a more precise tool with which to model similarity between events, since it is already made to model similarity between persons and objects. Second, counterpart theory provides a richer resolution to ATTACHMENT: the counterpart relation attaches possible events to actual ones via counterparthood. (More on this below.) Without it, nearness of worlds must do all the work. Third, counterpart theory avoids the problem of identity holding between two very different events (for example, Barack Obama's speech and an airplane safety check.) Fourth, I agree with (Wasserman (MS)) that there are independent reasons for applying a counterpart-theoretic treatment to events.

${ }^{9}$ Here I diverge from the traditional Lewisian framework in which only objects and persons have counterparts.
} 
ascriptions. To get a better handle on this idea, it will be helpful to illustrate what it is for an object to have de re modal ascriptions. Roughly, an object has a de re property $p$ if it is possibly $p$. For example, an unformed lump of clay has the de re property possibly a statue, and thus it has a counterpart at another possible world that is a statue. A plurality of grapes has the de re property possibly wine, and thus has a quantity of wine as an other-worldly counterpart.

We can apply the same framework to events. First, events are worldbound: an event occurs at only one world, but it can have numerous otherworldly counterparts. Counterparts model de re modal ascriptions: roughly, an event $e^{*}$ is a counterpart of $e$ if $e^{*}$ is possibly $e .{ }^{10}$ Consider the event the technician's having a snack. Suppose that, during that time, the technician could have been performing the safety check, but didn't. To say that the technician failed to perform the safety check is to ascribe to the actual event the technician's having a snack the de re modal property possibly being a safety check. The actual event (the technician's having the snack) ${ }^{11}$ has the safety check as a counterpart.

Event counterparthood is both context-sensitive and vague. A single event will often have multiple contextually-identified counterparts. The array of multiple counterparts supplied by context is appropriate for modeling omissions, since a single actual event (for example, the technician's eating lunch) will be an omission of potentially infinite others (singing karaoke, buying an iPad), depending on context. For instance, the technician might have also promised Joe that he would attend karaoke during the time the safety check was supposed to occur. We can easily imagine contextual invocations of both omissions: "He failed to perform the safety check" (by his boss) and "He failed to sing karaoke" (by a friend). Different contexts evoke different counterparts. Both unactualized possibilities - the safety check, and the karaoke - are counterparts of the actual world event that occurred in their places.

\footnotetext{
${ }^{10}$ Like Lewis on objects and persons, I take counterparthood to be asymmetric and intransitive: if $a$ is an event-counterpart of $b, b$ is not necessarily an event-counterpart of $a$. And if $a$ is an event-counterpart of $b$, and $b$ is a counterpart of $c, a$ is not necessarily an event-counterpart of $c$.

${ }^{11}$ In cases where there is not one clear time or place where the omitted event was to occur, I take the actual relatum to be disjunctive, e.g., a safety check at location A on the tarmac OR at location B on the tarmac. This result is superior to the Disjunctive Event Strategy because it is much less problematic to hold that disjuncts are causally salient than to hold that they are causes.
} 
The account applies to inanimate events as well as agents. Consider "The drought caused the famine." Here, the spatiotemporal region where the rain was to have fallen has a rainstorm at a possible world as a counterpart. Since there is a nearby possible world where the rainstorm occurs, the rainstorm at the possible world and the dry spatiotemporal region at the actual world are counterparts. ${ }^{12}$

\subsection{Absential versus Omissive Causal Claims}

A similar and plausible theory of omissions takes an omissive causal claim to identify an unactualized possibility minus the relationship to any actual event. ${ }^{13}$ On this view, "The technician's failure to perform the safety check caused the plane to crash" identifies only the technician performing the safety check at a possible world. Why take the omission to involve an actual event at all?

Because contextual elements in causal talk implicate an actual event in each omissive causal claim. In our case, it is predicated of the technician snacking that he could have been performing the safety check during that time. Even omissive causal claims that don't make explicit reference to an actual event still implicitly invoke actual events. Consider just the omissive portion of the above causal claim: "There was no safety check." In a causal context, this portion clearly implies "There was no safety check at the place and time it should have occurred and involving the person that should have performed it" rather than "There was no safety check (by anyone, ever, in the history of the universe.)" The place and time it should have occurred and the activities of the person who should have performed it function as the actual-world grounds for the possible safety check. Even when the actual-world event in the omission is referentially veiled, the tripartite model matches the hidden structure of omissive causal claims.

One claim can have both an absential and an omissive reading. For example, we might construe "There was no safety check" as "There was no safety check simpliciter [independent of time, place, or actual event]". Contextually, this claim refers to an

\footnotetext{
${ }^{12}$ Methodological note: I do not take there to be a meaningful linguistic distinction between events, persons, and objects in causal contexts. "The technician" is shorthand for "The event in which the technician participated during a particular period of time." I.e., causal claims involving persons and objects are shorthand for causal claims involving events.

${ }^{13}$ Thanks to Bernard Kobes for drawing attention to this view.
} 
absence, but not an omission. An omissive claim by nature invokes an actual thing (event, person, spatiotemporal location) that was to have been involved in the omitted event, whereas a mere absential claim straightforwardly denies the existence of the event. Omissions figure into causal claims; mere absences rarely do.

This difference is evident in the semantics of both types of claims. I will give a very brief sketch here.

Mere absences obey what Schaffer (2012) calls "The Semantic Premise," according to which absence claims involve straightforward negative existential quantification over events. For example, "There was no safety check" has the following Davidsonian rendering: ${ }^{14}$

$$
\sim(\exists e) \text { (Safety Check }(e) \text { ) }
$$

interpreted as "There is no event that is a safety check" or, more colloquially, "A safety check didn't occur."

In contrast, the omissive construal involves an unspecified actual event and its de re predicate, meriting the following semantic treatment:

$$
\exists e \diamond(\operatorname{Safety} \operatorname{Check}(e))
$$

Or, translated into counterpart theory:

(3) $\exists e\left(\mathrm{I} e @ \& \exists \mathrm{w} \exists e^{*}\left(\mathrm{Ww} \& \mathrm{I} e^{*} \mathrm{w} \& C e^{*} e \&\left(\operatorname{Safety} \operatorname{Check}\left(e^{*}\right)\right)\right)\right)$

to be interpreted as "There is an actual event that could have been a safety check." Claims whose best interpretation is (1) refer to absences rather than omissions: they are straightforward negative existential assertions about events. Claims whose best interpretation is (2) or (3) refer to omissions: they implicitly or explicitly appeal to a relationship between the actual and the possible.

\footnotetext{
${ }^{14}$ Schaffer follows Davidson (1967) in applying first-order predicate logic to events as well as objects.

${ }^{15}$ Here I follow Lewis' (1968) semantics for counterpart theory, where Wx: $\mathrm{x}$ is a world, lxy: $\mathrm{x}$ is in world $y$, @ $\mathrm{x}$ : $\mathrm{x}$ is actual, and Cxy: $\mathrm{x}$ is a counterpart of $\mathrm{y}$.
} 
Causal claims involve omissions rather than absences. Omissive claims contain hidden counterfactual structure; absential claims do not. For example, "The technician's failure to perform the safety check caused the plane to crash" isn't a mere denial of the existence of the safety check. Rather, it implicitly asserts that had the technician performed the safety check, the plane would not have crashed. Even the shortened versions of omissive claims (for example, "There was no safety check") have modal readings in causal contexts. The possibilities framework does justice to this idea and distinguishes nicely between modal claims and straightforward negative existential assertions.

\subsection{Closeness of Worlds}

In addition to a counterpart theoretic relationship between actual and possible events, my framework makes use of closeness of worlds. Omissive causal talk naturally selects worlds close to actuality. More precisely: an event is an omission if (i) had the omitted event occurred, the effect would not have occurred, and (ii) the omitted event occurs at a world close to actuality.

Consider the following causal claims about the safety check case:

(a) The technician failed to perform the safety check.

(b) Barack Obama failed to perform the safety check.

(c) Abraham Lincoln failed to perform the safety check.

Intuitively, (b) and (c) seem wrong for the following reason: a great many things would have to be different about our world such that either Obama or Lincoln performed the safety check. For example, Obama must know that the safety check must be performed, know how to perform it, and be in a position to perform it. Similarly for Abraham Lincoln, with the additional stipulation that Lincoln's performing the safety check requires his resurrection from the dead.

The possibilities treatment can make use of distance from actuality to account for the differences between (a), (b), and (c). Call the world where the technician performs the 
safety check T-world; the world where Obama performs the safety check O-world; and the world where Lincoln performs the safety check L-world. We can model the relative closeness of all three worlds based on how much would have to change about our world such that the absent events occur. Worlds like O-World and L-World, where much has to be changed in order for the omitted event to occur, are less similar to our world than those where very little must be changed, such as T-World.

Often, when an omission involves an agent, lack of epistemic and physical constraints on the agent's ability to participate in the omitted event places that world close to actuality. In our example, Barack Obama has no idea that a safety check must be performed: many features of our world would have to be changed (including Obama's knowledge of planes) in order for an Obama safety check to occur. Similarly, countless features of the world must change for Abraham Lincoln to perform the safety check (including time travel or magical feats of raising the dead).

Contextual invocations of $\mathrm{O}$-world and L-world are rare but conceivable: presidents are secretly charged with performing one safety check a term but Obama has not been told; Lincoln has been notified by a time traveller that he must travel forward in time to perform a safety check. Given the existence of outré contexts in which Obama's safety check and Lincoln's safety check are counterparts of the actual world failure, context-sensitivity is a benefit of, rather than a detriment to, the possibilities view: we can model strange contexts as well as everyday ones.

The contextual flexibility of counterpart theory is also helpful in sorting omissions from mere absences. Absences, as an entire class of things that don't happen, occur both far from actuality and near it. Omissions, the privileged subclass of absences, have portions that occur only close to actuality. There are countless non-happenings at any given time and at any given place: a goblin war where you are sitting, a flood in lower Los Angeles, the eruption of the state of Arizona into civil war-- but context rarely specifies these absences as omissions. Consider the (real-life) headline "Earthquake; MTA Service Not Affected." The headline selects the world where the MTA is affected as close to our world. The omissive claim identifies the counterpart event of the MTA's running on time as the event of the trains not running on time due to the earthquake- - the 
event that didn't happen, but very nearly could have. It would be contextually inappropriate for the headline to read "Earthquake; Manhattan Civil War Doesn't Occur”: though the Manhattan Civil War is an absence, it is not, in context, an omission: nothing about our world created conditions conducive to an intra-city civil war during the time period in question. ${ }^{16}$

Following Lewis' view of counterparthood of objects and persons, I take counterparthood between events to be a matter of contextually identified similarities between them. Closeness of worlds and counterparthood are interdependent, since both involve similarities between worlds and events within those worlds. Lewis (1973) has this to say on the relationship between counterparthood and closeness of worlds:

“... since closeness of worlds and counterpart relations among their inhabitants are alike matters of comparative similarity, the two are interdependent. At a world close to ours, the inhabitants of our world will have mostly close counterparts; at a world very different from ours, nothing can be a close counterpart of anything in our world." (Lewis, 1973)

Close worlds have more counterparts to items in our world due to similarities between them.

Different contexts emphasize different dimensions of similarity and thus pick out different counterparts. For example, we can imagine multiple contextually specified counterparts of the technician's snacking at the actual world: the technician's performing the safety check at one possible world, and the technician's singing karaoke at another possible world. Context emphasizes the involvement of the technician as the salient similarity between events. But the context could easily identify another dimension of similarity between events, such as the performance of a safety check (by Barack Obama, or by Abraham Lincoln). Such a general dimension of similarity isn't often invoked: the context in which any president performs the safety check is abnormal at best.

The elasticity of de re modal predication doesn't imply that closeness of worlds is entirely context-dependent. A traditional similarity metric for possible worlds that relies

\footnotetext{
16 The way I am using the term, only omissions are causally salient. I discuss causal salience at length in 3.4 .
} 
on large matches of spacetime fact places T-World closer to actuality than O-World and A-World, given the greater physical differences between O-Worlds and A-Worlds and actuality. Context intervenes by emphasizing certain dimensions of similarity over others.

\subsection{The Puzzles Reconsidered}

Return to our four puzzles. First, recall ATTACHMENT, the puzzle concerning why omissions "attach" to certain actual events but not to others. For example, the failure to perform the safety check seems like it belongs, in some sense, to the airplane technician but not to Barack Obama.

The de re modal framework easily handles this puzzle by attaching omissions to actual world events with the counterpart relation: the technician performing the safety check is a counterpart of the technician's actual-world activities at the time he should have been performing it. But (on most contexts) Barack Obama's performing the safety check is a counterpart of neither the technician's actual-world activities nor Obama's actual-world activities.

Context rarely selects something so general as anyone performing the safety check as the relevant dimension of similarity between events. Now, there do exist contexts in which something so general is the salient similarity: suppose that it is a well-known fact that the very fate of the world depends on someone (anyone!) performing the safety check at the time in question. Then we can understand the context in which everyone who failed to perform the safety check has performing the safety check as a counterpart. The idea is that omissions attach to actual-world events via contextually specified dimensions of similarity, and context plays the right role in selecting these dimensions of attachment.

Next, return to PRIVILEGED ABSENCES, the puzzle concerned with the difference between omissions and mere absences. On the possibility framework, there are two differences between omissions and absences. First: omissions have possible components that occur close to actuality, whereas absences occur far from actuality. For example: the possible world where the technician performs the safety check is closer to actuality than the possible world where Barack Obama performs the safety check.

Second: semantically, mere absences don't implicate actual-world events as counterparts. 
Absences are straightforward negative existential claims ("There is no goblin war") rather than transworld claims involving de re predication.

Let us now turn to CONFLICT, the idea that granting omissions causal efficacy conflicts with an exclusive commitment to positive being. So far, I've been silent on the causal status of omissions. It seems obvious that unactualized possibilities, which are spatiotemporally disconnected from actuality, cannot be causes of actual-world events. A natural objection, then, is that taking possibilities to be part of omissions does not strictly allow causation by omission. Perhaps the most this model gives us is a causal explanation of omissions, but not causation by omission. ${ }^{17}$

There is recent precedent for treating causation (and dependent concepts like moral responsibility) as a transworld relation. Schaffer (2005) holds that causation is a quaternary transworld relation between actual events and contrasts: $c$ rather than $c^{*}$ causes $e$ rather than $e^{*}$, where $c^{*}$ and $e^{*}$ are unactualized relata. Dowe (2009) argues that possibilities are causally relevant, if not fully causal. And Sartorio (2011) holds that unactualized possibilities are always relevant to moral responsibility of agents.

Nonetheless, I do not think that possibilities are causes of actual events: there is no transworld causation. I also deny that de re modal features of the actual world are causal. ${ }^{18}$ But this concession isn't as devastating for causation by omission as one might think. We can still hold that the omission is causally salient. This way, we account for the intuition that the omission of the safety check "belongs" to the technician while retaining a one-worldly causal relation between positive events. Causation is a one-worldly relation; causal salience is a transworld relation.

On my usage, salience is metaphysical, not merely explanatory: it is a property an event has in virtue of being a counterpart of an actualized event and being located at a world reasonably close to actuality. Short of taking the causal relata to be properties or

\footnotetext{
${ }^{17}$ Beebee (2004) argues for such a view. I discuss this view in more detail below.

${ }^{18}$ It might fall out of some counterfactual theories that de re modal properties are causal. For example, there being something that is necessarily the cat on the mat will have the same counterfactual consequences as there being a cat on the mat. I don't take this to imply that objects or events can have the causal powers that genuine causation by omission needs. Thanks to Daniel Nolan for this point.
} 
facts, upon which omissions are literally causal, this is the best we can do for resolving CONFLICT: we retain a commitment to positive being while granting omissions some causally important metaphysical status. Aside from being the best we can do for resolving CONFLICT, it is also good enough: there is no independent reason to treat absences as genuine members of positive being. The metaphysical status of omissions isn't intrinsically important; we are trying to account for their role in causal claims. What we are specifically trying to account for is the idea that certain absences but not others are causally relevant. But we are not antecedently concerned with granting omissions fullblooded existence. Moreover, doing so would fail to model their proper intuitive and metaphysical place: conceptually, causally relevant omissions occupy a place between total non-being and full-fledged being. Taking omissions to be possibilities strikes the right ontological balance between nonexistence and existence. Identifying a metaphysical (rather than merely explanatory) relationship between actual events and unactualized possibilities does justice to their causal relevance without granting them the same status as positive events.

Denying transworld causation also has the following benefit: while causation is not a vague or context-dependent matter, causal salience is. If omissions are literally causal, then applying a counterpart-theoretic treatment to events yields a vague and context-dependent causal relation. One might be comfortable with vagueness and context-dependence in the causal relation, but many metaphysical realists about causation oppose such an analysis. If causal salience is the explanandum, then it is no problem to say that context raises particular counterparts to salience, or that it is a vague matter which omissions are causally salient.

One might be concerned that causal salience is then entirely a matter of context, calling into question the truth conditions of such claims. But context-dependence doesn't eliminate truth evaluability simpliciter; it merely relativizes truth conditions to a context. For example, the omissive reading of "Abe Lincoln's failure to perform the safety check caused the plane to crash" is straightforwardly false in contexts that don't involve time 
travel. ${ }^{19}$ And "The technician's failure to perform the safety check caused the plane to crash" will be true in most normal contexts, since a large percentage of the worlds closest to ours contain no barriers to the technician fixing the plane.

Finally, consider SALIENCE, the idea that even if there are profligate counterfactual dependencies between non-occurrences and effects, only a select few are causally salient. Within the possibility framework, SALIENCE is resolved by taking only omitted events that occur at worlds close to actuality to be causally salient. For example, the world where Barack Obama performs the safety check is not salient to the plane crash because it doesn't occur close to actuality, whereas the safety technician's safety check occurs very close to actuality.

There is no sharp cutoff for causal salience; that is; there is no single world where an event switches from salient to a particular outcome to non-salient to that outcome. For example, consider a scenario in which an aviation hobbyist is in the vicinity of the plane when the safety check is to occur, but doesn't know that the paid airline technician will neglect his duties. There are no epistemic or physical barriers to the hobbyist performing the safety check on the plane: security is not watching the plane, and the hobbyist knows how to run all of the relevant procedures. Does the hobbyist's failure to check the plane count as an omission? The possibilities framework does not yield a sharp cutoff. Certainly, the world where the hobbyist performs the safety check is closer to actuality than the world where Obama performs the safety check. The comparative verdict is clear, but the absolute verdict is unclear. The vagueness of causal salience is appropriate for modeling causal verdicts in these uncertain cases.

Here is a recap. I have presented and defended the idea that the hidden structure of omissive causal claims is best modeled in the framework of de re possibility: an omission identifies an actual event, a possible event close to actuality, and a counterpart relation between them. Context selects dimensions of similarity between events in virtue of which they are counterparts. Omissions, which have a tripartite structure, are a

\footnotetext{
${ }^{19}$ But the absential reading is true, since there is a distant possible world where Abraham Lincoln performs the safety check.
} 
privileged subclass of mere absences. Within this framework, we resolve many puzzles about omissions and have a clearer picture of their semantic structure and their metaphysical roles.

\section{Omissions and Moral Responsibility}

In this section I'll briefly outline how taking omissions to be possibilities models moral data about omissions. The goal will be to give a sketch of the ways that the possibilities framework is useful for modeling moral data, and to give an honest account of its limitations. I will first argue that my analysis succeeds at modelling cases in which moral responsibility for an outcome depends primarily on epistemic and physical availability to bring about an outcome. Then I will present challenges for the framework.

\subsection{Closeness to Actuality and Moral Responsibility}

Intuitively, agents are only morally responsible for salient omissions. Reconsider the problem of profligate omissions. If all absences are omissions, and all omissions are causes, then (depending on one's views on the relationship between causation and moral responsibility), there is also profligate moral responsibility: every person who fails to check the plane (including Abe Lincoln and Barack Obama) is morally responsible for the plane crash.

Above, I used distance from actuality to model causal salience: events at close worlds are more causally salient than events at farther worlds. Modal distance provides an easy framework for modeling the judgment that the technician is morally responsible for the plane crash, but Barack Obama and Abe Lincoln are not: a great many things about the world would have to be different in order for Obama or Lincoln to have performed the safety check. Above, we saw how epistemic and physical constraints limit causal salience of a particular omission. Given the widely accepted principle that "ought implies can," it is natural that these constraints also play a role in selecting which omissions yield moral responsibility: an agent at a world in which fewer changes would have to occur in order for him to perform the omitted event is in a world closer to actuality. A world in which it would be reasonable to hold Barack Obama morally responsible for the plane crash is one in which he knows about the negligence of the 
technician, is in close proximity to the plane, and knows how to perform a safety check-all major physical differences between that world and the actual one. ${ }^{20}$

Physical and epistemic constraints also model moral differences between similar absences. Consider the following cases, which together I call Three Bystanders:

(Negligent Bystander) Bystander sees Victim stop breathing. Bystander knows the Heimlich maneuver, but doesn't administer it, and Victim dies.

(Ignorant Bystander) Bystander sees Victim stop breathing. Bystander doesn't know the Heimlich maneuver and so can't administer it, and Victim dies.

(Incapacitated Bystander) Bystander sees Victim stop breathing. Bystander knows the Heimlich maneuver, but is physically incapacitated and so can't administer it. Victim dies.

Like the safety check, distance from actuality reflects moral differentiation between the three failures to administer the Heimlich maneuver. In (Negligent Bystander), the bystander is responsible for Victim's death because he could have administered the Heimlich maneuver: there are no physical or epistemic barriers to his performing the Heimlich maneuver, and so the world where he performs the Heimlich maneuver is close to actuality. In (Ignorant Bystander), the bystander isn't responsible for Victim's death because he doesn't know the Heimlich maneuver: there is an epistemic barrier to his saving Victim. Thus the world where he performs the Heimlich maneuver is farther from actuality than the world where (Negligent Bystander) performs the Heimlich maneuver. Similarly with (Incapacitated Bystander): since there is a physical obstacle to performing the Heimlich maneuver, the world where incapacitated bystander saves Victim is farther from actuality than the world where Negligent Bystander does.

\subsection{Problems for the Relationship Between Modal Distance and Moral Responsibility}

In many cases, an agent's comparative moral responsibility for an outcome is modeled by closeness to actuality. But I will now present some challenges for the relationship between modal distance and moral responsibility. In some cases, an agent's

\footnotetext{
20 I assume Lewis' (1979c) similarity metric over possible worlds, which prizes large regions of spatiotemporal match as placing worlds close together in modal space. Though there are problems for this account, I will not concern myself with them here.
} 
omitted action occurs close to actuality, but she is not morally responsible for the outcome. In other cases, an agent's omitted action occurs far from actuality, but she is morally responsible for the outcome. And there are also cases in which agents are differentially morally responsible for outcomes that result from omitted actions at worlds equally close to actuality.

What do these cases demonstrate about the relationship between distance from actuality and moral responsibility? I will not attempt a comprehensive answer here ${ }^{21}$, but I will conclude that there are cases in which distance from actuality and moral responsibility come apart: close modal distance of the omitted action is neither necessary nor sufficient for moral responsibility for an outcome. I take modal distance to be a useful heuristic for modeling some moral data, but not all cases can be modeled in this way. I turn now to these and related issues.

\subsubsection{Problem: Personality Traits and Dispositions as World-Ordering}

In some cases, an agent's personality and dispositions place her involvement in an omitted outcome far from actuality even when she is morally responsible for a given outcome. ${ }^{22}$ This situation occurs when an agent isn't disposed to do something that she is physically and epistemically able to do. Consider the following example:

(Negligent Bystander) Bystander sees Victim stop breathing. Bystander knows the Heimlich maneuver, but doesn't administer it, and Victim dies.

(Racist Bystander) Racist Bystander sees Victim (who is a member of a race Racist Bystander despises) stop breathing. Racist Bystander knows the Heimlich maneuver, but doesn't administer it, and Victim dies.

Here, the possible world where Racist Bystander performs the Heimlich maneuver is farther than the one where Negligent Bystander performs the Heimlich maneuver, even though both are, intuitively, equally morally responsible for Victim's death. Similarly, we can construct a case with a selfish airplane technician who is disposed to eat his lunch rather than perform the safety check, even though he is physically and epistemically able to perform it. Since personalities and dispositions don't exculpate, what should we make

\footnotetext{
${ }^{21}$ For more on this topic, see my "Omission Impossible" (MS).

22 Thanks to David Boonin, Carolina Sartorio, and Justin Weinberg for pressing me on this point.
} 
of these cases?

First, note that urgency plays a large role in many of the cases we have examined. Thus the examples that have been my focus have concerned the agent's ability to bring about an outcome in a thin sense rather than a thick sense..$^{23}$ By this I mean that we are looking at a very small slice of the world that isolates the agent and her abilities from her prior dispositions. Personalities and dispositions have large temporal spread that precedes the small time slices under examination. That an agent has, in the past, failed to save choking bystanders doesn't restrict her ability to save this choking person in this moment. Nor does the fact that the technician has been lazy in the past restrict his ability to perform that safety check in the small period of time when it must occur. Ability to perform urgently-needed outcomes is indexed to the particular time slice when it must occur.

Now, some psychological features do restrict ability. Severe depression, for example, might affect one's ability in an urgent moment to bring about the morally required outcome. Suppose that the airline technician is so depressed that he can't leave the couch in the break room in order to perform the safety check. Depression affects his ability to perform the right action in the moment, rather than being a mere disposition or prior pattern that is morally irrelevant to an urgent outcome. Presumably this condition is more exculpatory than mere laziness.

How can we model omissions that don't involve urgency? Consider the claim “The pharmacological company's failure to run a trial resulted in the patients' deaths." Even though the drug trial is necessary to prevent deaths, it doesn't share the same urgency as saving a choking bystander. So we cannot judge the drug company's ability to run the drug trial in the "thin" sense. And suppose that the pharmacological company is disposed to neglect drug trials - in the past it hasn't run them (and it simply hasn't been caught). In virtue of the disposition towards negligence, the world where the drug company runs the trial is farther from actuality than the one where it doesn't. But intuitively, the mere fact of the disposition doesn't morally absolve the drug company.

${ }^{23}$ Thanks to Owen Flanagan for this way of formulating the point. 
This case and similar ones can be handled by invoking a separate omission: the failure of the drug company to previously correct its harmful disposition. Each neglected drug trial is also a failure to correct a damaging pattern. By transitivity, the failure of the drug company to correct its disposition causes it to neglect to run the drug trial, which ultimately kills patients. Similarly with any agent who forms a harmful disposition: if Jane forms a habit of neglecting to feed her pet, her failure to correct her disposition transmits responsibility to the final and unavoidable pet-killing. The idea is that certain dispositions are under the control of the agent. If an outcome is the result of a harmful disposition that she failed to correct, then she is responsible for the outcome in virtue of failing to correct the disposition that led to the outcome. The idea is that agents can be responsible for certain worlds being closer or farther away based on their responsibility for their own traits and dispositions. This antecedent responsibility enters into the moral responsibility calculus, even if not through causal salience. ${ }^{24}$

\subsubsection{Remoteness from Actuality With Moral Responsibility}

Some cases to do not have such a clean fix. Consider:

(Sharks) Suzy comes upon a drowning child and fails to jump in and save him. Unbeknownst to Suzy, she could not have saved him, because there were sharks in the water that would have eaten her before she got to the child. ${ }^{25}$

In this case, Suzy's saving the child is far from actuality for reasons extrinsic to and unbeknownst to her: the presence of sharks in the water that would have eaten her had she jumped in. It is a controversial matter whether she is morally responsible for the child's death, but let us assume that she is. Given this assumption, distance from actuality comes apart from moral responsibility in the following way: Suzy's moral responsibility for the child's death is the result of an omitted action - saving the child - that occurs at a possible world far from actuality. Even though there are no nearby worlds in which Suzy succeeds in saving the child, she is morally responsible for the child's death because she failed to jump in the water and save him.

\footnotetext{
${ }^{24}$ Thanks to Alex Guerrero for this way of framing it.

25 This case is adapted from Fischer and Ravizza (1999).
} 
"Frankfurt-style" cases can be constructed to demonstrate the same point. For example, consider:

(Frankfurted Babysitter) Suzy promises to babysit little Billy. But Suzy forgets. Consequently, no one babysits little Billy. Unbeknownst to Suzy, if she hadn't forgotten to babysit little Billy, an evil neuroscientist scientist would have intervened and prevented Suzy from remembering to babysit. ${ }^{26}$

The nearest possible worlds in which Suzy remembers to babysit are worlds in which the evil neuroscientist intervenes and induces her forgetfulness in any case. Thus the worlds where Suzy successfully babysits Billy are far from actuality. Yet Suzy is morally responsible for failing to babysit Billy despite the modal distance between her babysitting and actuality.

Both (Sharks) and (Frankfurted Babysitter) share the following structure: the agent omits to perform an action that she could not have performed anyway. Factors extrinsic to her place her involvement in the desired outcome far from actuality, and yet the modal distance does not morally exculpate the agent for her failure to bring about the outcome. These cases suggest that modal closeness of an omitted action isn't a necessary condition on moral responsibility: an agent can be morally responsible for omitting to bring about an outcome even if bringing about the outcome is far from actuality.

\subsubsection{Closeness to Actuality Without Moral Responsibility}

Nor is close modal distance sufficient for moral responsibility. For there are cases in which an agent's involvement in an outcome is very close to actuality, and yet the agent is not morally responsible for the outcome. Consider the following case:

(Electrolytes) Unbeknownst to Billy, Suzy will die in five minutes unless she gets a sudden jolt of electrolytes. He contemplates pouring salt into her drink as a mean joke, but ultimately decides against it. Suzy dies. ${ }^{27}$

In this example, Billy's omitted action (pouring salt into Suzy's drink) is very close to actuality, and yet Billy is not morally responsible for Suzy's death. Despite the modal

\footnotetext{
${ }^{26}$ This example is adapted from Clarke (1994). Thanks to Stephen Kearns for drawing my attention to it.

27 Thanks to Rachael Briggs for this case.
} 
closeness of the omitted act that holds in virtue of Billy's physical proximity and his temptation to pour the salt, Billy's ignorance of Suzy's health requirement morally exculpates him from his role in Suzy's death. As in (Sharks) and (Frankfurted Babysitter), distance from actuality and moral responsibility come apart. But they do so in the opposite way: the agent's involvement in the outcome is close to actuality, and yet this closeness is not sufficient for moral responsibility for the outcome. Though Billy's delivery of electrolytes to Suzy is close to actuality, he is not morally responsible for Suzy's death. Cases such as this make clear that modal closeness is not sufficient for moral culpability in general.

These lessons do not mitigate the usefulness of the possibilities framework for modeling moral responsibility for omissions. Rather, the lessons demonstrate that the framework is most useful for modeling scenarios in which epistemic and physical features of agents are the most salient ones in moral evaluation. The limits of the possibilities framework are helpful as well: they identify scenarios in which the features most salient to moral evaluation concern things other than the agent's epistemic and physical availability to bring about an outcome. And there are also examples in which an agent's physical availability and epistemic ability to bring about an outcome are morally relevant, and yet do not fully determine the moral features of the case. In these cases, the possibilities framework is useful in separating different targets of moral evaluation. I turn now to such examples.

\subsubsection{Norm Selected Pairs}

There are also cases where there are multiple candidates for the world closest to actuality-- where there are no epistemic or physical constraints, and yet common sense selects one world over alternatives. For example, suppose that an off-duty technician is in

the vicinity of the plane when the safety check is to occur, but does not perform the safety check. Very few changes to the world would have had to occur for the off-duty technician to perform the safety check. Is the off-duty technician morally responsible for the plane crash? Intuitively, many say no.

In a similar and oft-used example, a negligent neighbor promises to water a plant 
while Jane is out of town, fails to water the plant, and the plant dies. Intuitively, the neighbor's failure to water the plant (rather than Barack Obama's failure to water the plant) is the cause of the plant's death. Now suppose that a nosy neighbor with physical access to the plant walks by the (visibly wilting) plant every day that Jane is gone but fails to water it. Many have the intuition that the nosy neighbor is not responsible for the plant's death because she didn't promise to water it, but the negligent neighbor is. Metaphysically, no feature of the world where nosy neighbor waters the plant places it closer to actuality than the world where negligent neighbor waters the plant, and yet many judge the negligent neighbor to be (solely) responsible for the plant's death.

With these sorts of cases in mind, Beebee objects to the closeness of worlds strategy on the grounds that "the norms are doing the work by themselves, as it were, rather than merely informing our judgments about closeness of worlds." ${ }^{28}$ In other words, moral assessments rather than non-normative features of worlds create our judgments about which worlds are closest to actuality. Consider the following example of this normative bias affecting world-ordering: the world where negligent neighbor waters the plant is closer than the world where nosy neighbor waters the plant, simply because negligent neighbor promised to water the plant but nosy neighbor didn't. ${ }^{29}$ Nonnormative features of worlds don't locate one closer to actuality than the other. But commonsense moral reasoning seems to select the world where the negligent neighbor waters the plant as the closest due to the existence of a norm in one case but not in the other. Call these sorts of cases norm selected pairs. There is a norm selected pair when there are two agents whose physical and epistemic circumstances with respect to a given outcome are the same, yet normative judgments place one world closer to actuality than the other.

My response to the objection from norm selected pairs comes in several parts. First, I deny that one world is closer to actuality than the other. In norm selected pairs, both worlds are equally close to the actual world: negligent technician world and off-duty

\footnotetext{
${ }^{28}$ Beebee (2004), p. 26.

${ }^{29}$ One might also have the opposite intuition that Nosy Neighbor world is closer than Negligent Neighbor world. Either way, my view holds that both worlds are equally close to actuality. Thanks to Elizabeth Harman for this point.
} 
technician world are equally close to actuality, as are negligent neighbor world and nosy neighbor world. We should rely on the non-normative features of worlds to guide judgments of closeness even if they leave comparative moral evaluations in these types of cases more open to debate.

Second: in some cases the worlds' equal modal distance from actuality yield the correct moral result without the intervention of a norm. This is particularly so when an outcome involves urgency. Consider a case in which a surgeon-on-call is beckoned to an operating room to perform life-saving surgery on a patient. The surgeon shows up, but stands idly around the operating room, leading to the patient's death. Now suppose that there is another "off duty" surgeon idling lazily in the operating room while waiting for a ride home, and this surgeon also fails to perform the life-saving surgery, preferring instead to check Facebook. Both surgeons are morally responsible for the patient's death, even if one was contractually bound to perform the surgery and the other wasn't. Structurally, this case is like the dual technicians and the dual neighbors: both agents fail to bring about a certain outcome, only one of whom is contractually obligated to do so. But intuitively, both agents are morally responsible for the patient's death. Given that there are no epistemic or physical constraints on the actions of either agent, it is appropriate to judge each as morally responsible. The case also suggests that distance from actuality does most of the work in modeling moral responsibility in cases where the urgency of bringing about an outcome outweighs other normally unequalizing contractual and normative obligations. In other words, an urgently-needed outcome (such as a lifesaving surgery) is an "equalizer" with respect to moral obligation, whereas in non-urgent circumstances a norm such as a contract plays a role in differentiation of moral obligation.

Third: two worlds being equally close to actuality underdetermines rather than fixes the relevant moral attributions. Their equal modal distance provide the foundation for norms to do additional work. The claim is not that both agents' obligations are necessarily the same given that both worlds are close to actuality. Rather, their equal footing underdetermines their comparative obligations, leaving room for a normative element (for example, a contract) to yield moral obligation. This is an important point, 
since my goal is not to straightforwardly derive "oughts" from a metaphysics of causation. Rather, the idea is to correctly model the metaphysical situation of each agent so that we can think more clearly about the role that epistemic ability and physical availability to bring about an outcome play in moral obligation with respect to that outcome. Distance from actuality plays a larger role in some cases, such as those in which moral responsibility for bringing about the outcome depends largely on physical and epistemic ability. Three Bystanders is such an example. In other cases, norms play a larger role in determining and differentiating moral responsibility, as in Negligent Neighbor and Nosy Neighbor.

I will not further defend my view against norm selected pairs, but I will reiterate a few lessons from them. We should not allow norms themselves to order worlds with respect to omissive claims. Rather, we should allow closeness of worlds to model comparative physical availability and epistemic ability of agents to bring about outcomes, even if agents' actions at equally close worlds underdetermine moral assessment. In cases where urgency doesn't "equalize" moral obligation, normative features provide additional grounds for moral obligation, but don't directly influence ordering of worlds.

\subsection{Singer's Argument as a Norm Selected Pair}

I will now apply my framework to a well-known argument that I take to involve a norm selected pair: Peter Singer's argument for the moral obligation to give to charity in order to save starving children. That argument ${ }^{30}$ likens failing to give to charity to failing to save a drowning child on the way to work for fear of sullying one's clothes: in both cases, he argues, one is failing to save a life even if one can. Spatial distance doesn't mitigate moral responsibility, and so we are each morally obligated to send money to charity to save the starving child just as we are obligated to save the drowning child. Famously, Singer defends the following principle: “[...] if it is in our power to prevent something bad from happening, without thereby sacrificing anything of comparable moral importance, we ought, morally, to do it." (1972, p. 31) According to Singer, if we can prevent the deaths of people who are starving by sending money to charity (without

\footnotetext{
${ }^{30}$ See Singer's "Famine, Affluence, and Morality" (1972).
} 
losing anything of similar moral importance), then we must. ${ }^{31}$ Construed metaphysically, the "if it is in our power" in Singer's famous principle is an ordering of worlds: since we are physically and epistemically able to send money to charity in the same way that we are physically and epistemically able to save a drowning child in close proximity, we are bound by the same moral obligation in both cases. ${ }^{32}$

Given this metaphysical construal of Singer's principle, I suggest that an agent's failing to save the drowning child and an agent's failing to give to charity constitute a norm selected pair. Both cases contain agents with no physical or epistemic obstacles to bringing about their respective outcomes: in one case, saving a drowning child, and in another case, sending money to charity in order to save a starving child. Yet, intuitive moral judgments place the world where the agent saves the drowning child closer to actuality than the world where the agent prevents distant deaths by charitable contributions.

There are several points worth noting. There are no obvious moral differentiators such as contracts or promises that distinguish the moral status of saving the child from the moral status of giving to charity: it is not as if the agent has signed a contract or made an explicit promise to rescue all drowning children and failed to sign one about rescuing distant starving children. Unlike Negligent Neighbor/ Nosy Neighbor, there is no easily identifiable moral asymmetry between the cases owing to a contract or promise. The norm selected pair demonstrates why Singer's argument is resistant to attempts to establish a disanalogy between saving the drowning child and giving to charity: agents are as equally physically and epistemically able to give to charity as they are to save the drowning child. If one accepts that equal physical and epistemic ability to bring about the outcome correctly models the moral situation, then it is very difficult to wriggle out of Singer's conclusion, given that the two omissions are modally on par.

Framing Singer's argument as a norm selected pair yields two useful suggestions. First: the intuitive resistance to the idea that we are obligated to save the drowning child

\footnotetext{
${ }^{31}$ Here I follow Unger (1995) as interpreting Singer's "ought" as one that means "We must do it" rather than "It would be better to do it than not to do it."

${ }^{32}$ By "epistemic ability," I mean that an agent knows about the problem and knows how to solve it.
} 
but not obligated to give to charity partially stems from a difference in dispositions, a la Racist Bystander. We are disposed to save a drowning child, but not disposed to give to charity. Singer might respond with the transmission-of-responsibility strategy: we are morally required to correct our harmful disposition not to give to charity. ${ }^{33}$

Second: a compelling avenue of response against Singerian obligation requires a new set of principles for ordering worlds that isn't based primarily on epistemic ability and physical availability of agents to bring about outcomes. A promising strategy is to argue that giving-to-charity world is not as close to actuality as saving-the-drowningchild world. I will not attempt such a strategy here: I am compelled by Singer's argument intrinsically and I accept the implication that our moral obligation is the same in both cases. But I hope that the identification of Singer's argument as a norm selected pair will open a new avenue of exploration for the classic argument.

\section{Conclusion}

I have argued that omissive causal talk is best modeled in the framework of de re modal possibility. A counterpart-theoretic treatment of events, in addition to contextually ordered worlds, meet many explanatory desiderata for a metaphysics of omissions. Such a model also easily accounts for commonsense moral evaluations of omission-involving outcomes. With a de re modal model of omissive causal claims, we can better understand their role in causation, causal explanation, and moral responsibility.

\section{References}

Beebee, H. "Causing and Nothingness" (2004). In L. A. Paul, E. J. Hall \& J. Collins (eds.), Causation and Counterfactuals.

Bernstein, S. “Omission Impossible” (ms).

Clarke, R. "Intentional Omissions," Nous 44 (2010), 27-35. “Absence of Action” (2012) Philosophical Studies 158 (2):361-376.

\footnotetext{
33 Thanks to Carolina Sartorio for this way of formulating the connection.
} 
----- "Ability and Responsibility for Omissions" (1994) Philosophical Studies 73 pp. 195208.

Dowe, P. Physical Causation. (2000) New York: Cambridge University Press.

----- "The Power of Possible Causation" (ms).

Fischer, J.M. "Responsibility and Failure". (1985) Proceedings of the Aristotelian Society New Series, Vol. 86, pp. 251-270.

Lewis, D. (1968) “Counterpart Theory and Quantified Modal Logic" Journal of Philosophy Volume 65, Issue 5, 113-126.

(1979c) “Counterfactual Dependence and Time's Arrow” Nô̂s, 13: 455-476.

(1973) "Counterfactuals and Comparative Possibility" Journal of Philosophical

Logic 2 (4):418-446

McGrath, S. (2005) "Causation by Omission: a Dilemma" Philosophical Studies 123 (12):125--48.

Sartorio, C. (2011) “Actuality and Responsibility” Mind 120 (480): 1071-1097.

----- (2010). "The Prince of Wales Problem for Counterfactual Theories of Causation" in New Waves in Metaphysics (Hazzlett, ed.)

----- (2006) “Disjunctive Causes” Journal of Philosophy 103 (10):521-538 (2006)

Schaffer, J. (2005) “Contrastive Causation” Philosophical Review 114 (3): 327-358.

------ (2012) “Disconnection and Responsibility” Legal Theory 18 (Special Issue 04): $399-435$

Singer, P. (1972) "Famine, Affluence, and Morality" Philosophy and Public Affairs (1) 3: $229-243$.

Thomson, J. (2003) “Omissions" Philosophy and Phenomenological Research Vol LXVI, No. 1.

Unger, P. (1995) Living High and Letting Die. Oxford: Oxford University Press.

Wasserman, R. "Is Causation Extensional?" (ms) 
